\title{
INTUSSUSCEPTION OF THE BOWEL IN AN INFANT
}

\author{
FOLLOWED BY OBSTRUCTION OF THE BOWELS WITH A SECOND INTUSSUS- \\ CEPTION WITHIN THREE WEEKS AFTER THE \\ FIRST OPERATION *
}

A. PESKIND, M.D.

CLEVELAND

History.-Ann J., born Feb. 18, 1915, was taken ill during the evening of June 14, 1915, with some abdominal distress. The family physician, Dr. S. Peskind, saw the child the following day and, suspecting intussusception, advised the child's immediate removal to the hospital. The child arrived at the East Fifty-Fifth Street Hospital June 15 and was taken to the operating room at $5: 30 \mathrm{p} . \mathrm{m}$.

First Operation.-The lower end of the ilium, appendix, cecum, and part of the ascending colon were found telescoped into the transverse colon. When liberated the incarcerated bowel appeared very dark-gangrenous in spots. The age of the child and a pulse scarcely perceptible while under anesthesia precluded any attempts at resection of the devitalized viscus. The appendix, almost black in appearance, was quickly tied off and removed. The wound was closed and the child left the operating room with a very feeble heart action. The operation itself required less than fifteen minutes. At $6: 15 \mathrm{p}$. m. the baby, then in its bed, had a temperature of about $100 \mathrm{~F}$., pulse over 180 , respirations between 56 and 60 . The child, as soon as she recovered from the anesthetic, was given a few drops of Vichy water every ten or fifteen minutes and was put to the mother's breast for a few minutes at 10 in the evening. The child vomited a few times after the operation. A saline injection was given at 11 in the evening, which was expelled with flatus and was tinged with blood. The following day the temperature went up to $103.2 \mathrm{~F}$., pulse 180 and over. Within forty-eight hours the temperature and pulse reached the normal. The recovery seemed complete within nine days and the little patient was sent home June 24, apparently free from signs of any gastro-intestinal disturbance.

Second Operation.-At 10:15 a. m., July 8, just three weeks after the first operation, the child was brought back to the East Fifty-Fifth Street Hospital with symptoms of acute obstruction of the bowels. Some resistance was felt in the cecal region, also in the middle of the transverse colon. The child looked hopelessly ill. The abdomen was opened and several inches of the ascending colon were found telescoped in the transverse part of the colon. This second intussusception was easily released and the bowel had a normal appearance. At the site of the first intussusception, however, were found the greatest foci of pathologic activity. The cecum and part of the ilium were both matted and bound together by unyielding adhesions. The lumen of the bowel felt as if it were obliterated. The only chance for the restoration of the continuity of the lumen of the bowel was to resort to ileocecostomy, and this was done. The child, not quite 5 months old, bore the operation seemingly without any additional shock. It required just twenty-six minutes to disengage the intussusception, to make the anastomosis, and to close the abdominal wound. Scarcely any gastro-intestinal difficulties followed the second operation, but

* Submitted for publication May 17, 1917. 
a double pneumonia developed on the third day and the baby had to fight for its life for nearly two weeks. The temperature often exceeded $105 \mathrm{~F}$. and the pulse rate over 180 per minute. The child remained in the hospital about a month after the second operation and was sent home Aug. 10, 1915. It is now a year and nine months since the child was operated on and at no time since has she evinced any sign of intestinal or pulmonary disturbances.

The interesting points to be drawn from this case are that it is almost impossible to measure with certainty a baby's power of resistance, and at the same time it emphasizes to me the seriousness of the surgeon's position in such cases, when he dares attempt the possibility of saving a human life in spite of apparent hopelessness. .

2414 East Fifty-Fifth Street. 